\title{
Quality of Life Among Bipolar Disorder Patients Misdiagnosed With Major Depressive Disorder
}

\author{
A. George Awad, Ph.D., F.R.C.P.; Krithika Rajagopalan, Ph.D.; \\ Susan C. Bolge, Ph.D.; and Diana D. McDonnell, Ph.D.
}

\begin{abstract}
Objective: Bipolar disorder is frequently misdiagnosed as major depressive disorder (MDD). We aim to quantify the prevalence of misdiagnosed bipolar disorder among the depression population and evaluate the quality-of-life
\end{abstract} (QOL) impact of misdiagnoses.

Method: Data were collected from 2 selfadministered, cross-sectional studies in 2003. Patients participating in The Bipolar Disorder Misdiagnosis Study ( $\mathrm{N}=1156)$ were previously diagnosed with depression, experienced a depressive episode within the past year, and had no previous diagnosis of bipolar disorder or schizophrenia. Patients who experienced a manic episode in the past year, based on DSM-IV criteria, were classified as misdiagnosed. Patients participating in The Bipolar Disorder Project $(\mathrm{N}=1214)$ selfreported a diagnosis of bipolar disorder and were recruited through community mental health centers and support groups. Quality of life was assessed via the Psychological General Well-Being (PGWB) Index and Medical Outcomes Study 8-Item Short-Form Health Survey (SF-8). Demographic differences between groups were controlled using linear regression models.

Results: Of the diagnosed MDD sample, $14.3 \%$ met criteria for misdiagnosed bipolar disorder. When controlling for demographic differences, the PGWB overall score for the misdiagnosed averaged $12.77(\mathrm{p}<.001)$ points lower than that of MDD patients and $9.55(\mathrm{p}<.001)$ points lower than that of diagnosed bipolar disorder patients. The average SF-8 mental component summary score for the misdiagnosed was 5.85 $(\mathrm{p}<.001)$ points lower than that of MDD patients and $3.18(\mathrm{p}=.002)$ points lower than that of diagnosed bipolar disorder patients.

Conclusion: Misdiagnosis is associated with poorer QOL than MDD or diagnosed bipolar disorder, which are recognized as having a considerable impact on QOL.

(Prim Care Companion J Clin Psychiatry 2007;9:195-202)
Received Aug. 24, 2006; accepted Dec. 8, 2006. From the Humber River Regional Hospital, Toronto, Ontario, Canada (Dr. Awad), AstraZeneca Pharmaceuticals, LP, Wilmington, Del. (Dr. Rajagopalan); and Consumer Health Sciences, Princeton, N.J. (Drs. Bolge and McDonnell)

This study was funded by AstraZeneca Pharmaceuticals, $L P$, Wilmington, Del.

Poster presented of earlier study analysis at the Fourth European Stanley Conference, Sept. 23-25, 2005, Aarhus, Denmark.

Dr. Awad serves as a consultant for Janssen, Eli Lilly, Pfizer, and AstraZeneca. Dr. Rajagopalan was an employee of AstraZeneca at the time of the study. Drs. Bolge and McDonnell have no other financial affiliations related to the subject of this article.

Corresponding author and reprints: Susan C. Bolge, Ph.D. Consumer Health Sciences, 116 Village Blvd., Suite 200, Princeton, NJ 08540 (e-mail:susan.bolge@chsinternational.com).

B ipolar disorder, a chronic affective disorder characterized by depression and at least 1 manic episode, is more prevalent than previously believed. It is predicted that the lifetime prevalence of bipolar disorder ranges from $1 \%$ to $8 \% .^{1-8}$ As research continues into the subtypes of bipolar disorder, many experts believe that bipolar disorder may be as widespread as unipolar depression, though not as widely recognized. ${ }^{9-10}$ Bipolar symptoms have been associated with significant functional impairment, often having a negative impact on the performance of work-related, leisure, and interpersonal activities. ${ }^{11}$ Many studies have also found that quality of life (QOL) is compromised in people with bipolar disorder, even during periods of clinical remission. ${ }^{12-14}$

Bipolar disorder is at least as detrimental to life quality as several chronic medical conditions. Arnold and colleagues' comparison of people with bipolar disorder and chronic back pain using the Medical Outcomes Study 36-Item Short-Form Health Survey (SF-36) ${ }^{12}$ found that those with bipolar disorder had similar impairments to their mental well-being as those with chronic pain, and substantial impairment in health-related QOL compared with the general population. Cooke and colleagues' similar comparisons ${ }^{13}$ also found that the SF-20 scores of people with bipolar disorder were within or below the mean scores reported for people with chronic medical illness and major depression. Thus, even in clinical remission, bipolar disorder is associated with marked reductions in self-reported well-being, confirming the importance of the disorder as a major public health problem.

For bipolar disorder to be properly researched, evaluated, and treated, it must first be recognized and accurately 
diagnosed. The 1992 National Depressive and ManicDepressive Association (NDMDA) (now known as the Depression and Bipolar Support Alliance) constituent survey, and its update in 2000 , found that long delays between the onset of symptoms, seeking of treatment, and receipt of an accurate diagnosis were overwhelmingly common among people with bipolar disorder. ${ }^{15,16}$

Bipolar disorder is commonly misdiagnosed as unipolar depression, ${ }^{15-18}$ possibly because people with bipolar disorder often initially present for treatment of depression. When asked about hypomanic symptoms, many do not report them, either because others do not comment on these symptoms or because there is little impairmentand sometimes even improved functioning-associated with them. ${ }^{17}$

Misdiagnosing bipolar disorder as unipolar depression has important clinical implications. The misdiagnosed are often treated with only antidepressant medications, which may lead to a worsening of the course of illness and deprive the patient of the potential benefits of appropriate medications. ${ }^{17}$ In Ghaemi and colleagues' chart reviews of outpatients with affective disorder diagnoses, $23 \%$ of those misdiagnosed with depression experienced a new or worsening rapid-cycling course attributable to antidepressant use. ${ }^{19}$

Further emphasizing the need for and benefits of early diagnosis, Lish and colleagues' review of the initial NDMDA data found that, when bipolar disorder was identified earlier, fewer personal, social, and work-related problems were experienced. ${ }^{15}$ Research has also found that the more patients themselves know about their condition, the better their QOL. ${ }^{19}$ Few (if any) studies, however, have directly evaluated how diagnosis (or lack thereof) affects QOL.

In this study, we conducted cross-sectional, national surveys of people diagnosed with either depression or bipolar disorder to assess (1) the prevalence of misdiagnosed bipolar disorder and (2) the QOL impact of accurate diagnoses.

\section{METHOD}

\section{Sampling Design and Data Collection}

The study sample comprised subjects from 2 separate surveys conducted by Consumer Health Sciences (Princeton, N.J.): The Bipolar Disorder Misdiagnosis Study (BpDMS) and The Bipolar Disorder Project (BpDP).

The BpDMS was an Internet-based survey conducted in March 2003. The BpDMS sample consisted of 1156 patients who reported that they were diagnosed with depression by a health care provider. Participants were identified through Consumer Health Sciences' 2002 National Health and Wellness Survey (NHWS) ${ }^{20}$ an annual crosssectional study of attitudes, behaviors, and treatment choices of health care consumers. NHWS respondents are recruited through a privately maintained, nationally representative consumer panel. As an incentive to participate in first the NHWS and then the BpDMS, patients were provided with points that are accumulated over time and exchanged for retail products. The objectives of the BpDMS were to quantify the proportion of the depressed population who exhibit manic symptoms associated with bipolar disorder (misdiagnosed bipolar) and to determine the drivers of misdiagnosis. Of those who were invited to complete the BpDMS, 25\% responded. Of those who responded, $56 \%$ met the following inclusion criteria: (1) diagnosed depression, (2) depressive episode within the past year, (3) not diagnosed with bipolar disorder, and (4) not diagnosed with schizophrenia.

The BpDP is a semiannual longitudinal study of patients who reported that they were diagnosed with bipolar disorder by a health care provider. Patients, identified through local chapters of the Depression and Bipolar Support Alliance and Community Mental Health Centers, complete a 12-page paper survey at each wave of the study. The following analyses include 1214 patients who either participated in May 2003 or who entered the study as part of a replenishment wave in November 2003. As an incentive to participate, centers were given $\$ 20$ per completed questionnaire to use at their discretion, and respondents were given a 6-month subscription to the Harvard Health Letter.

Protocols of the BpDMS and BpDP were not reviewed by an independent review board (IRB). Self-reported data collection techniques include very limited risk to participants. ${ }^{21,22}$ Participation in both studies was voluntary and did not include any clinical or drug interventions. Respondents to both studies were assured that confidentiality would be maintained and no identifying information would be revealed to anyone. In the NHWS and BpDMS, no identifying information about panel members is released. Therefore, the working data files contain no identifying information about patients except for a panel identification number, used to link data between NHWS and BpDMS. In the BpDP, patients were provided with instructions for returning completed questionnaires and envelopes in which to seal them. Each patient was provided with an identification number that is the only identifying information in the working data. Identification numbers and contact information were linked and sealed separately for use in mailings of incentives and future questionnaires. Thus, while a formal ethics committee review was not performed, all the necessary procedures to ensure patient protections and confidentiality were implemented in this study.

\section{Survey Measures \\ Misdiagnosed bipolar disorder, diagnosed major de- pressive disorder, and diagnosed bipolar disorder. The American Psychiatric Association's (APA) Diagnostic and Statistical Manual of Mental Disorders, Fourth Edition}


defines a manic episode as "a period of abnormally and persistently elevated, expansive or irritable mood, lasting for at least 1 week." ${ }^{23(\mathrm{p} 362)}$ The patient must also experience at least 3 of the following (4 if the mood is only irritable): inflated self-esteem or grandiosity, decreased need for sleep, more talkative than usual or pressure to keep talking, flight of ideas or subjective experience that thoughts are racing, distractibility, increased goaldirected activity of psychomotor agitation, and excessive involvement in pleasurable activities that have a high potential for painful consequences. In addition, symptoms must cause significant impairment in social, occupational, or other daily life activities. ${ }^{23}$

As all 1156 respondents to the BpDMS described above were diagnosed with depression and had experienced a recent depressive episode, the occurrence of manic symptoms was assessed to identify those who probably had bipolar disorder. Respondents were asked if, during the past year, they had experienced any of the following symptoms for at least 1 week: increased energy, activity, or restlessness; racing thoughts and rapid talking; excessive "high" or excited feelings; decreased need for sleep; unrealistic beliefs in their own abilities or powers; unusually poor judgment; increased irritability; being easily distracted; increased sex drive; unusual or aggressive behavior; or abuse of alcohol, recreational drugs, or prescription medications. Those who reported manic symptoms were subsequently asked how much these symptoms interfered with their regular daily activities, using a 5-point scale from "did not interfere at all" (1) to "was unable to do regular daily activities" (5). Respondents were classified as experiencing a manic episode in the past year and therefore being misdiagnosed if they experienced at least 4 of the above symptoms and reported that these symptoms interfered in their regular daily activities at least moderately (i.e., 3,4 , or 5 on the 5 -point scale).

All other respondents to the BpDMS were classified as experiencing major depressive disorder (MDD). That is, patients diagnosed with depression and experiencing a depressive episode but not a manic episode in the past year. All respondents to the BpDP were classified as diagnosed with bipolar disorder, regardless of recent manic or depressive episodes. (Of the diagnosed, 59\% experienced a manic episode in the past year, and 70\% experienced a depressive episode in the past year.)

Quality of life. Quality of life was evaluated using 2 validated scales. The Psychological General Well-Being (PGWB) Index ${ }^{24}$ consists of 22 questions designed to measure individuals' subjective feelings of well-being or distress related to 6 QOL concepts: anxiety, depressed mood, self-control, well-being, general health, and vitality. The PGWB provides a subscale for each concept as well as an overall well-being score. Overall scores range from 0 to 110, with higher scores indicating greater psychological well-being. ${ }^{25}$
The SF- ${ }^{26}$ is a multipurpose, generic measure of health status based on the SF-36, ${ }^{27}$ which is widely used to monitor the health of general and specific populations. This comprehensive scale yields summary measures of physical and mental health-related QOL. As documented, the SF-36 has proven useful in comparing the burden of different diseases, differentiating the health benefits produced by different treatments, and screening individual patients. The questions included in the SF-8 are scored on the same norm-based metric as the SF-36 scales and summary measure and can be compared directly to those obtained with other SF generic health surveys. The 8 items are individually validated, as are the summary measures. The normative score for the U.S. adult population is 50 , with a standard deviation of \pm 10 ; higher scores indicate higher QOL. ${ }^{26,27}$

\section{Statistical Analysis}

Pairwise comparisons for the following 3 groups were performed: misdiagnosed bipolar disorder versus MDD, misdiagnosed bipolar disorder versus diagnosed bipolar disorder, and diagnosed bipolar disorder versus MDD. Mean PGWB overall and subscale scores and mean SF-8 mental component summary scores were compared. Significance testing was performed using 2-tailed t tests at an $\alpha$ level of .05 for each pairwise comparison. This method was chosen over the use of analysis of variance across the 3 categories, because pairwise comparisons allow for the identification of differences between each specific pair and not just the assumption that the largest difference between groups is causing the significance.

Multivariate analyses were performed using linear regression models to control for age, gender, race/ethnicity, education, and marital status. All statistical analyses were conducted using SPSS 12.0 for Windows (SPSS Inc., Chicago, Ill.).

\section{RESULTS}

\section{The Misdiagnosed}

Among patients with MDD, 14\% were classified as having misdiagnosed bipolar disorder. The manic symptoms reported most frequently by the misdiagnosed patients were increased irritability (94\%), being easily distracted $(86 \%)$, and racing thoughts and rapid talking $(59 \%)$. More than half $(53 \%)$ of the misdiagnosed were "very" or "extremely worried" about their symptoms (> 3 on a 5-point scale).

Primary care physicians and specialists appear to be equally as likely to misdiagnose a patient with manic symptoms associated with bipolar disorder. Surprisingly, most of the misdiagnosed patients $(53 \%, \mathrm{~N}=62)$ report that they have spoken with a medical provider about their mania symptoms. Those who did speak to a medical provider were more likely to be "very" or "extremely" 


\begin{tabular}{|c|c|c|c|c|c|c|}
\hline \multirow[b]{2}{*}{ Variable } & \multirow[b]{2}{*}{$\begin{array}{l}\text { Misdiagnosed } \\
\quad(\mathrm{N}=166)\end{array}$} & \multirow[b]{2}{*}{$\begin{array}{c}\text { Depression } \\
(\mathrm{N}=990)\end{array}$} & \multirow[b]{2}{*}{$\begin{array}{c}\text { Bipolar } \\
(\mathrm{N}=1214)\end{array}$} & \multicolumn{3}{|c|}{ Significance (p value) } \\
\hline & & & & $\begin{array}{l}\text { Misdiagnosed } \\
\text { vs Depression }\end{array}$ & $\begin{array}{c}\text { Misdiagnosed } \\
\text { vs Bipolar }\end{array}$ & $\begin{array}{l}\text { Depression } \\
\text { vs Bipolar }\end{array}$ \\
\hline \multicolumn{7}{|l|}{ Demographic } \\
\hline Male, $\%$ & 45 & 37 & 37 & .055 & .071 & .797 \\
\hline Age, mean \pm SD & $41.7 \pm 13.3$ & $45.3 \pm 14.3$ & $44.8 \pm 12.3$ & .003 & .003 & .419 \\
\hline White, \% & 76 & 84 & 87 & .012 & .001 & .161 \\
\hline Married, \% & 27 & 27 & 38 & .905 & .009 & $<.001$ \\
\hline College degree, $\%$ & 33 & 30 & 33 & .387 & .885 & .166 \\
\hline \multicolumn{7}{|l|}{ Medication use, $\%$} \\
\hline Antidepressants & 57 & 56 & 60 & .798 & .581 & .117 \\
\hline Anxiolytics & 12 & 11 & 34 & .694 & $<.001$ & $<.001$ \\
\hline Mood stabilizers & 4 & 2 & 100 & .128 & $<.001$ & $<.001$ \\
\hline Antipsychotics & 7 & 1 & 60 & $<.001$ & $<.001$ & $<.001$ \\
\hline
\end{tabular}

\begin{tabular}{|c|c|c|c|c|c|c|}
\hline \multirow[b]{2}{*}{ Measure } & \multirow[b]{2}{*}{$\begin{array}{l}\text { Misdiagnosed } \\
(\mathrm{N}=166)\end{array}$} & \multirow[b]{2}{*}{$\begin{array}{l}\text { Depression } \\
(\mathrm{N}=990)\end{array}$} & \multirow[b]{2}{*}{$\begin{array}{c}\text { Bipolar } \\
(\mathrm{N}=1214)\end{array}$} & \multicolumn{3}{|c|}{ Significance ( $\mathrm{p}$ value) } \\
\hline & & & & $\begin{array}{l}\text { Misdiagnosed } \\
\text { vs Depression }\end{array}$ & $\begin{array}{c}\text { Misdiagnosed } \\
\text { vs Bipolar }\end{array}$ & $\begin{array}{l}\text { Depression } \\
\text { vs Bipolar }\end{array}$ \\
\hline \multicolumn{7}{|l|}{ PGWB score, mean $\pm \mathrm{SD}$} \\
\hline Overall & $46.2 \pm 18.0$ & $58.7 \pm 17.6$ & $56.7 \pm 20.6$ & $<.001$ & $<.001$ & .014 \\
\hline Anxiety & $10.2 \pm 4.9$ & $13.9 \pm 4.8$ & $12.8 \pm 5.6$ & $<.001$ & $<.001$ & $<.001$ \\
\hline Depressed mood & $6.9 \pm 3.5$ & $9.0 \pm 3.2$ & $8.8 \pm 3.6$ & $<.001$ & $<.001$ & .139 \\
\hline Self-control & $7.6 \pm 3.0$ & $9.9 \pm 2.8$ & $8.6 \pm 3.4$ & $<.001$ & .001 & $<.001$ \\
\hline Positive well-being & $7.6 \pm 3.7$ & $9.2 \pm 3.9$ & $8.9 \pm 4.4$ & $<.001$ & $<.001$ & .157 \\
\hline General health & $6.8 \pm 3.4$ & $8.2 \pm 3.2$ & $8.2 \pm 3.3$ & $<.001$ & $<.001$ & .902 \\
\hline Vitality & $7.0 \pm 3.8$ & $8.5 \pm 4.0$ & $9.4 \pm 4.3$ & $<.001$ & $<.001$ & $<.001$ \\
\hline $\begin{array}{l}\text { SF-8 mental component } \\
\quad \text { summary score, mean } \pm \text { SD }\end{array}$ & $35.8 \pm 11.0$ & $41.6 \pm 10.2$ & $39.2 \pm 12.5$ & $<.001$ & .001 & $<.001$ \\
\hline
\end{tabular}

worried about their manic symptoms; less able to perform regular daily activities; more likely to have been diagnosed with comorbid conditions of anxiety, insomnia, obsessive-compulsive disorder, and phobias; and more likely to be older, white, or married, with a higher household income.

Only $13 \%(\mathrm{~N}=8)$ of the misdiagnosed patients who had discussed manic symptoms with a doctor were currently being treated with a mood stabilizer or antipsychotic. Overall, the misdiagnosed were significantly less likely than those patients diagnosed with bipolar disorder to be taking mood stabilizers or antipsychotics. However, the misdiagnosed were slightly more likely to be taking an antipsychotic medication than those patients who were properly diagnosed with depression (Table 1).

The misdiagnosed were significantly more likely to be a member of a racial or ethnic minority group and to be younger than those patients with MDD or diagnosed bipolar disorder. Also, the misdiagnosed patients were significantly less likely to be married than those with diagnosed bipolar disorder (Table 1).

\section{Quality of Life}

In bivariate analyses, the misdiagnosed patients experienced consistently poorer average QOL than those who had been diagnosed with either MDD or bipolar disorder, on the basis of SF-8 and all PGWB scales ( $\mathrm{p}=.001$ or $\mathrm{p}<.001$ for all comparisons). Additionally, patients with diagnosed bipolar disorder experienced significantly poorer QOL than patients with MDD, as measured by the SF- 8 mental component summary score $(\mathrm{p}<.001)$ and the PGWB overall score $(\mathrm{p}=.014)$, anxiety score $(\mathrm{p}<.001)$, self-control score $(\mathrm{p}<.001)$, and vitality score $(\mathrm{p}<.001)$ (Table 2$)$.

When controlling for demographic variations between groups, the previously observed differences in QOL measures between the misdiagnosed patients, patients with MDD, and patients with bipolar disorder remained significant. The misdiagnosed patients averaged 12.77 points lower on the PGWB overall score $(\mathrm{p}<.001)$ and 5.85 points lower on the SF- 8 mental component summary score $(\mathrm{p}<.001)$ than patients with MDD (Table 3). The misdiagnosed patients averaged 9.54 points lower on the PGWB overall score $(\mathrm{p}<.001)$ and 3.18 points lower on the SF-8 mental component summary score $(\mathrm{p}=.002)$ than patients with diagnosed bipolar disorder (Table 4). Patients with diagnosed bipolar disorder averaged 2.24 points lower on the PGWB overall score $(\mathrm{p}=.008)$ and 2.52 points lower on the SF-8 mental component summary score $(\mathrm{p}<.001)$ than patients with MDD (Table 5). 


\begin{tabular}{|c|c|c|c|c|c|c|c|c|}
\hline \multirow[b]{3}{*}{ Variable } & \multicolumn{4}{|c|}{ PGWB Overall Score } & \multicolumn{4}{|c|}{ SF-8 Mental Component Summary Score } \\
\hline & \multicolumn{2}{|c|}{$\begin{array}{l}\text { Unstandardized } \\
\text { Coefficients }\end{array}$} & \multirow{2}{*}{$\begin{array}{c}\text { Standardized } \\
\beta \\
\end{array}$} & \multirow{2}{*}{$\begin{array}{l}\text { Significance } \\
\text { (p value) }\end{array}$} & \multicolumn{2}{|c|}{$\begin{array}{c}\text { Unstandardized } \\
\text { Coefficients }\end{array}$} & \multirow{2}{*}{$\begin{array}{c}\text { Standardized } \\
\beta\end{array}$} & \multirow{2}{*}{$\begin{array}{l}\text { Significance } \\
\text { (p value) }\end{array}$} \\
\hline & $\beta$ & SE & & & $\beta$ & SE & & \\
\hline Constant & 57.677 & 2.397 & , & $<.001$ & 39.754 & 1.411 & & $<.001$ \\
\hline Gender (male) & 2.883 & 1.117 & 0.077 & .010 & 0.111 & 0.658 & 0.005 & .866 \\
\hline Age & 0.015 & 0.042 & 0.012 & .721 & 0.045 & 0.025 & 0.061 & .069 \\
\hline Race (white) & -2.224 & 1.442 & -0.046 & .123 & -0.909 & 0.849 & -0.032 & .284 \\
\hline Married & 0.133 & 1.285 & 0.003 & .917 & 0.457 & 0.756 & 0.020 & .546 \\
\hline College degree & 3.871 & 1.195 & 0.094 & .001 & 1.454 & 0.703 & 0.061 & .039 \\
\hline $\begin{array}{l}\text { Misdiagnosed (1) vs } \\
\text { depression (0) }\end{array}$ & -12.766 & 1.504 & -0.247 & $<.001$ & -5.852 & 0.886 & -0.195 & $<.001$ \\
\hline $\mathrm{R}^{2 \mathrm{a}}$ & 0.075 & $\ldots$ & $\ldots$ & $<.001$ & 0.047 & $\ldots$ & $\ldots$ & $<.001$ \\
\hline Adjusted $\mathrm{R}^{2}$ & 0.070 & $\cdots$ & $\cdots$ & $\ldots$ & 0.042 & $\cdots$ & $\cdots$ & $\ldots$ \\
\hline
\end{tabular}

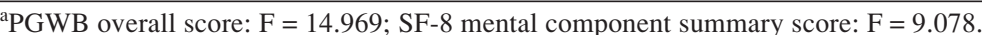

Abbreviations: PGWB = Psychological General Well-Being Index, SF-8 = Medical Outcomes Study 8-Item Short-Form Health Survey.

Table 4. Multivariate Models of Quality of Life by Mental Health Diagnosis Status (misdiagnosed vs. bipolar)

\begin{tabular}{|c|c|c|c|c|c|c|c|c|}
\hline \multirow[b]{3}{*}{$\underline{\text { Variable }}$} & \multicolumn{4}{|c|}{ PGWB Overall Score } & \multicolumn{4}{|c|}{ SF-8 Mental Component Summary Score } \\
\hline & \multicolumn{2}{|c|}{$\begin{array}{l}\text { Unstandardized } \\
\text { Coefficients }\end{array}$} & \multirow{2}{*}{$\begin{array}{c}\text { Standardized } \\
\beta\end{array}$} & \multirow{2}{*}{$\begin{array}{l}\text { Significance } \\
\text { (p value) }\end{array}$} & \multicolumn{2}{|c|}{$\begin{array}{l}\text { Unstandardized } \\
\text { Coefficients }\end{array}$} & \multirow{2}{*}{$\begin{array}{c}\text { Standardized } \\
\beta \\
\end{array}$} & \multirow{2}{*}{$\begin{array}{l}\text { Significance } \\
\text { (p value) }\end{array}$} \\
\hline & $\beta$ & SE & & & $\beta$ & SE & & \\
\hline Constant & 44.628 & 2.453 & & $<.001$ & 33.932 & 1.527 & & $<.001$ \\
\hline Gender (male) & 1.234 & 1.165 & 0.029 & .290 & 1.378 & 0.729 & 0.054 & .059 \\
\hline Age & 0.212 & 0.047 & 0.127 & $<.001$ & 0.109 & 0.029 & 0.110 & $<.001$ \\
\hline Race (white) & 0.362 & 1.651 & 0.006 & .827 & -0.590 & 1.034 & -0.017 & .568 \\
\hline Married & 0.862 & 1.223 & 0.019 & .481 & 0.066 & 0.759 & 0.003 & .931 \\
\hline College degree & 4.231 & 1.192 & 0.099 & $<.001$ & 0.621 & 0.742 & 0.024 & .403 \\
\hline $\begin{array}{l}\text { Misdiagnosed (1) vs } \\
\text { bipolar (0) }\end{array}$ & -9.547 & 1.710 & -0.154 & $<.001$ & -3.183 & 1.046 & -0.088 & .002 \\
\hline $\mathrm{R}^{2 \mathrm{a}}$ & 0.060 & $\ldots$ & $\ldots$ & $<.001$ & 0.026 & $\ldots$ & $\ldots$ & $<.001$ \\
\hline Adjusted $\mathrm{R}^{2}$ & 0.055 & $\ldots$ & $\ldots$ & $\ldots$ & 0.021 & $\ldots$ & $\ldots$ & $\ldots$ \\
\hline
\end{tabular}

${ }^{\mathrm{a} P G W B}$ overall score: $\mathrm{F}=13.308$; SF-8 mental component summary score: $\mathrm{F}=5.213$.

Abbreviations: PGWB = Psychological General Well-Being Index, SF-8 = Medical Outcomes Study 8-Item Short-Form Health Survey.

\section{DISCUSSION}

We found that people with bipolar disorder or depression, as well as those who were misdiagnosed, reported lower QOL than the norms for the general adult population. However, misdiagnosed bipolar disorder was associated with significantly poorer QOL than either MDD or diagnosed bipolar disorder, both of which are recognized by society as having a considerable impact on QOL. ${ }^{12-14}$ Antipsychotic medications and mood stabilizers are effective in treating bipolar disorder and improving outcomes by decreasing the frequency and severity of affective episodes ${ }^{28-34}$ However, the first step needed for successful treatment is proper diagnosis.

In addition to poorer QOL, people who had bipolar disorder that was diagnosed as depression were also more likely to be women and nonwhite. In a national survey of people with bipolar disorder, Hirschfeld and colleagues ${ }^{16}$ also found that women were significantly more likely than men to be misdiagnosed. Robb et al. ${ }^{35}$ determined that women may have later onset of mania and more depressive episodes, with the different course of illness possibly contributing to initially incorrect diagnoses.

Regarding race, Strakowski et al. ${ }^{36}$ similarly found that black patients were significantly more likely than white patients to receive a clinical diagnosis other than bipolar disorder, presumably because of differences in reported symptom profiles. Mukherjee et al. ${ }^{37}$ also concluded that black and Hispanic bipolar patients may be at a higher risk than whites for misdiagnosis. In their study, ethnicity remained significantly associated with misdiagnosis of bipolar disorder even after all other significant variables were controlled. ${ }^{37}$ As everyone in our sample had been diagnosed at least with depression, people with undiagnosed bipolar disorder had all received a mental health evaluation in the past. Further research is needed to identify the possible barriers - for both patients and clinicians-to recognizing and/or discussing symptoms of mania.

A number of limitations are worth noting, as they influence the interpretation of the results. Although based 


\begin{tabular}{|c|c|c|c|c|c|c|c|c|}
\hline \multirow[b]{3}{*}{ Variable } & \multicolumn{4}{|c|}{ PGWB Overall Score } & \multicolumn{4}{|c|}{ SF-8 Mental Component Summary Score } \\
\hline & \multicolumn{2}{|c|}{$\begin{array}{l}\text { Unstandardized } \\
\text { Coefficients }\end{array}$} & \multirow{2}{*}{$\begin{array}{c}\text { Standardized } \\
\beta\end{array}$} & \multirow{2}{*}{$\begin{array}{l}\text { Significance } \\
\text { (p value) }\end{array}$} & \multicolumn{2}{|c|}{$\begin{array}{l}\text { Unstandardized } \\
\text { Coefficients }\end{array}$} & \multirow{2}{*}{$\begin{array}{c}\text { Standardized } \\
\beta\end{array}$} & \multirow{2}{*}{$\begin{array}{c}\text { Significance } \\
\text { (p value) }\end{array}$} \\
\hline & $\beta$ & SE & & & $\beta$ & SE & & \\
\hline Constant & 50.340 & 1.833 & $\ldots$ & $<.001$ & 38.569 & 1.109 & $\ldots$ & $<.001$ \\
\hline Gender (male) & 1.950 & 0.877 & 0.049 & .026 & 0.439 & 0.534 & 0.018 & .412 \\
\hline Age & 0.160 & 0.033 & 0.109 & $<.001$ & 0.081 & 0.020 & 0.093 & $<.001$ \\
\hline Race (white) & -1.283 & 1.226 & -0.023 & .296 & -1.273 & 0.747 & -0.038 & .089 \\
\hline Married & 0.998 & 0.926 & 0.024 & .281 & 0.316 & 0.562 & 0.013 & .574 \\
\hline College degree & 4.199 & 0.913 & 0.102 & $<.001$ & 0.729 & 0.555 & 0.030 & .189 \\
\hline Bipolar (1) vs depression (0) & -2.246 & 0.851 & -0.058 & .008 & -2.522 & 0.518 & -0.109 & $<.001$ \\
\hline $\mathrm{R}^{2 \mathrm{a}}$ & 0.030 & $\ldots$ & $\ldots$ & $<.001$ & 0.022 & $\ldots$ & $\ldots$ & $<.001$ \\
\hline Adjusted $\mathrm{R}^{2}$ & 0.027 & $\ldots$ & $\ldots$ & $\ldots$ & 0.019 & $\ldots$ & $\ldots$ & $\ldots$ \\
\hline
\end{tabular}



Abbreviations: PGWB = Psychological General Well-Being Index, SF-8 = Medical Outcomes Study 8-Item Short-Form Health Survey.

on DSM-IV criteria, the classification of the misdiagnosed patients was not based on a validated instrument. The DSM-IV has some inherent limitations in that it may be too stringent in its durational requirements, and it does not consider course of illness, which can be a predictor of some forms of bipolar disorder. Many clinicians, including members of the APA DSM-IV task force, stress the importance of supplementing diagnostic tools with interviews, personal observations, and subjective, clinical judgment to reach the most reliable diagnoses. ${ }^{9,10,38}$ As more than half of the misdiagnosed patients reported speaking to a medical provider about manic symptoms, it is likely that, in some cases, a physician may have considered and correctly rejected a bipolar diagnosis. In this case, the prevalence of misdiagnosed bipolar disorder may be lower than measured here. However, as this study was not designed to assess symptoms of hypomania, the actual prevalence of misdiagnosed bipolar disorder may be higher than the conservative $14.3 \%$ measured here.

All of the data, on QOL as well as mental health diagnosis and QOL, were self-reported. Respondents were asked if they had been diagnosed (with depression or bipolar disorder) by a physician, but we did not validate this with medical records. However, because of the recruitment through support groups and chronic illness panels, people who did not have these conditions are unlikely to have been included.

Although this method of recruitment may have assured a properly identified sample, it may also have excluded those not seeking support or care. As such, this sample probably represents people more involved in their care and/or with better functioning. The low QOL reported by these individuals therefore is likely an underestimate of that reported by more isolated or severely impaired individuals.

The QOL outcome measures assessed here were also self-reported. In 2 previous studies evaluating the same scales used in this analysis (PGWB and SF-8), the QOL scales had an adequate applicability and internal validity when used with people with bipolar disorder. Leidy and colleagues ${ }^{38}$ used the Hamilton and Young Rating Scales to longitudinally validate QOL, while Thunedborg's group $^{39}$ successfully used QOL scales to predict recurrence of depression. Both demonstrated that people with bipolar disorder contributed reliable self-reports of their life quality. ${ }^{38,39}$ Similarly, the reliability of patients' self reports have been extensively demonstrated in other psychotic disorders including schizophrenia and schizoaffective disorders. ${ }^{40-42}$

As this was a cross-sectional, observational study, it is also possible that there were some unmeasured determinants of misdiagnosis that also explain lower life quality. Additional studies that longitudinally follow people through the diagnosis and disease process, and measure potential improvement or decline in QOL, are necessary to confirm these results. Nonetheless, the dramatically lower QOL we observed in people who most likely have bipolar disorder, but who have only been diagnosed with depression, is worthy of attention and follow-up.

This study identified several common characteristics of the misdiagnosed that may help clinicians identify individuals at risk of misdiagnosis and distinguish them from those with MDD. Clinicians should be vigilant in looking for a number of patient characteristic symptoms that may signal bipolar disorder, especially among patients who have experienced their first depressive episode and those undergoing antidepressant therapy. These symptoms and characteristics include mood switches; hypomania, especially immediately before or after a depressive episode; early age at onset; relatively acute onset; episodic frequency; greater percent of time ill; mood lability; motor retardation; greater time spent sleeping; extraversion; novelty seeking; postpartum mood episodes; seasonal mood disorders; and family history. $1,7,9,10$

Although it can be argued that some indicators, such as impulsivity and hyperthymic temperament, are best 
observed rather than discovered through questioning, it can be very useful for clinicians to explain these signs to both the patient and family, and to ask both to watch for signs in the patient's normal environment. ${ }^{1,9,10,43}$ More importantly, sufferers need tools to communicate their manic symptoms to their physicians, as the delay in seeking immediate treatment for early symptoms of mania is cited as the primary reason for bipolar disorder misdiagnoses, and proper clinical and therapeutic interventions best follow accurate diagnoses. ${ }^{44}$

\section{CONCLUSION}

Bipolar disorder is frequently unrecognized and misdiagnosed by medical practitioners, causing a significant number of patients to receive suboptimal treatment. In our study, among adults with MDD, $14 \%$ were classified as having misdiagnosed bipolar disorder. While MDD and diagnosed bipolar disorder are commonly recognized as having a considerable negative impact on QOL, we found that the misdiagnosed have significantly lower QOL, as measured by the PGWB and SF-8 mental component summary score, than patients with MDD or diagnosed bipolar disorder.

\section{REFERENCES}

1. Birnbaum HG, Shi L, Dial E, et al. Economic consequences of not recognizing bipolar disorder in patients: a cross-sectional descriptive analysis. J Clin Psychiatry 2003;64:1201-1209

2. Bryant-Comstock L, Stender M, Devercelli G. Health care utilization and costs among privately insured patients with bipolar I disorder. Bipolar Disord 2002;4:398-405

3. Dunner DL. Clinical consequences of under-recognized bipolar spectrum disorder. Bipolar Disord 2003;5:456-463

4. Kleinman LS, Lowin A, Flood E, et al. Costs of bipolar disorder. Pharmacoeconomics 2003;21:601-622

5. Montgomery SA, Keck PE. First International Exchange on Bipolar Disorder. J Affect Disord 2000;59(suppl 1):S81-S88

6. Peele PB, Xu Y, Kupfer DJ. Insurance expenditures on bipolar disorder: clinical and parity implications. Am J Psychiatry 2003;160:1286-1290

7. Stender M, Bryant-Comstock L, Phillips S. Medical resources use among patients treated for bipolar disorder: a retrospective, crosssectional, descriptive analysis. Clin Ther 2002;24:1668-1676

8. Thase ME. New approaches to managing difficult-to-treat depressions. J Clin Psychiatry 2003;64(suppl 1):3-4

9. Bowden CL. Strategies to reduce misdiagnosis of bipolar depression. Psychiatr Serv 2001;52:51-55

10. Manning JS. Difficult-to-treat depressions: a primary care perspective. J Clin Psychiatry 2003;64(suppl 1):24-31

11. Calabrese JR, Hirschfeld RM, Reed M, et al. Impact of bipolar disorder on a US community sample. J Clin Psychiatry 2003;64:425-432

12. Arnold LM, Witzeman KA, Swank ML, et al. Health-related quality of life using the SF-36 in patients with bipolar disorder compared with patients with chronic back pain and the general population. J Affect Disord 2000;57:235-239

13. Cooke RG, Robb JC, Young LT, et al. Well-being and functioning in patients with bipolar disorder assessed using the MOS 20-ITEM short form (SF-20). J Affect Disord 1996;39:93-97

14. Robb JC, Cooke RG, Devins GM, et al. Quality of life and lifestyle disruption in euthymic bipolar disorder. J Psychiatr Res 1997;31: 509-517

15. Lish JD, Dime-Meenan S, Whybrow PC, et al. The National Depressive and Manic-Depressive Association (NDMDA) survey of bipolar members. J Affect Disord 1994;31:281-294

16. Hirschfeld RM, Lewis L, Vornik LA. Perceptions and impact of bipolar disorder: how far have we really come? results of the National Depressive and Manic-Depressive Association 2000 survey of individuals with bipolar disorder. J Clin Psychiatry 2003;64:161-174

17. Simpson SG, McMahon FJ, McInnis MG, et al. Diagnostic reliability of bipolar II disorder. Arch Gen Psychiatry 2002;59:736-740

18. Ghaemi SN, Boiman EE, Goodwin FK. Diagnosing bipolar disorder and the effect of antidepressants: a naturalistic study. J Clin Psychiatry 2000;61:804-808

19. Dogan S, Sabanciogullari S. The effects of patient education in lithium therapy on quality of life and compliance. Arch Psychiatr Nurs 2003; $17: 270-275$

20. Consumer Health Sciences. The National Health and Wellness Survey. Available at: www.nhwsurvey.com. Accessed 2005

21. Babbie E. The Practice of Social Research, 7th ed. Belmont, Calif: Wadsworth Publishing Company; 1995

22. Singleton RA, Straits BC, Straits MM. Approaches to Social Research, 2nd ed. New York, NY: Oxford University Press; 1993

23. American Psychiatric Association. Diagnostic and Statistical Manual of Mental Disorders, Fourth Edition, Text Revision. Washington, DC: American Psychiatric Press; 2000

24. Dupuy, HJ. The Psychological General Well-Being Index (PGWB). In: Wenger NK, Mattson ME (eds). Assessment of Quality of Life in Clinical Trials of Cardiovascular Therapies. New York, NY: Le Jacq Publishing Inc; 1984

25. Revicki DA, Leidy NK, Howland L. Evaluating the psychometric characteristics of the Psychological General Well-Being Index with a new response scale. Qual Life Res 1996;5:419-425

26. Ware JE, Kosinski M, Dewey JE, et al. How to Score and Interpret Single-Item Health Status Measures: A Manual for Users of the SF-8 Health Survey. Lincoln, RI: QualityMetric Incorporated; 2001

27. Ware JE, Kosinski M, Keller SD. SF-36 Physical and Mental Health Summary Scales: A User's Manual. Boston, Mass: The Health Institute; 1994

28. Altamura AC, Salvadori D, Madaro D, et al. Efficacy and tolerability of quetiapine in the treatment of bipolar disorder: preliminary evidence from a 12-month open-label study. J Affect Disord 2003;76:267-271

29. Chengappa KN, Baker RW, Shao L, et al. Rates of response, euthymia and remission in two placebo-controlled olanzapine trials for bipolar mania. Bipolar Disord 2003;5:1-5

30. Keck PE, Versiani M, Potkin S, et al. Ziprasidone in the treatment of acute bipolar mania: a three-week, placebo-controlled, double-blind, randomized trial. Am J Psychiatry 2003;160:741-748

31. Keck PE, Marcus R, Tourkodimitris S, et al. A placebo-controlled, double-blind study of the efficacy and safety of aripiprazole in patients with acute bipolar mania. Am J Psychiatry 2003;160:1651-1658

32. Suppes T, Webb A, Paul B, et al. Clinical outcome in a randomized 1-year trial of clozapine versus treatment as usual for patients with treatment-resistant illness and a history of mania. Am J Psychiatry 1999;156:1164-1169

33. Tohen M, Sanger TM, McElroy SL, et al. Olanzapine versus placebo in the treatment of acute mania: olanzapine HGEH Study Group. Am J Psychiatry 1999;156:702-709

34. Segal J, Berk M, Brook S. Risperidone compared with both lithium and haloperidol in mania: a double-blind randomized controlled trial. Clin Neuropharmacol 1998;21:176-180

35. Robb JC, Young LT, Cooke RG, et al. Gender differences in patients with bipolar disorder influence outcome in the medical outcomes survey (SF-20) subscale scores. J Affect Disord 1998;49:189-193

36. Strakowski SM, McElroy SL, Keck PE, et al. Racial influence on diagnosis in psychotic mania. J Affect Disord 1996;39:157-162

37. Mukherjee S, Shukla S, Woodle J, et al. Misdiagnosis of schizophrenia in bipolar patients: a multiethnic comparison. Am J Psychiatry 1983; 140:1571-1574

38. Leidy NK, Palmer C, Murray M, et al. Health-related quality of life assessment in euthymic and depressed patients with bipolar disorder: psychometric performance of four self-report measures. J Affect Disord 1998;48:207-214

39. Thunedborg K, Black CH, Bech P. Beyond the Hamilton depression scores in long-term treatment of manic-melancholic patients: prediction of recurrence of depression by quality of life measurements. Psychother Psychosom 1995;64:131-140 
40. Awad AG, Hogan TP, Voruganti LN, et al. Patient's subjective experiences on antipsychotic medications implications for outcome and quality of life. Int Clin Psychopharmacol 1995;10(suppl 3):123-132

41. Voruganti LNP, Heslegrave RJ, Awad AG, et al. Quality of life measurement in schizophrenia: reconciling the quest for subjectivity with the question of reliability. Psychol Med 1998;28:165-172

42. Awad AG, Voruganti LNP. The subjective/objective dichotomy in schizophrenia: relevance to nosology research and management. In:
Gaebel W (ed). Zukunftsperspektivien in Psychiatries Und Psychoterapie Darmstadt. Steinkopff Verlag; 2002

43. McElroy SL, Strakowski SM, West SA, et al. Phenomenology of adolescent and adult mania in hospitalized patients with bipolar disorder. Am J Psychiatry 1997;154:44-49

44. Roukema R, Fadem B, James B, et al. Bipolar disorder in a low socioeconomic population: difficulties in diagnosis. J Nerv Ment Dis 1984; 172:76-79 